\begin{tabular}{|c|c|}
\hline Citation & $\begin{array}{l}\text { Helsen F, De Meester P, Van Keer J, Gabriels C, Van De Bruaene A, } \\
\text { Herijgers P, Rega F, Meyns B, Gewillig M, Troost E, Budts W. } \\
\text { Pulmonary outflow obstruction protects against heart failure in adults } \\
\text { with congenitally corrected transposition of the great arteries. Int J } \\
\text { Cardiol. } 2015 \text { Oct 1;196:1-6. }\end{array}$ \\
\hline Archived version & $\begin{array}{l}\text { Author manuscript: the content is identical to the content of the } \\
\text { published paper, but without the final typesetting by the publisher }\end{array}$ \\
\hline Published version & http://linkinghub.elsevier.com/retrieve/pii/S0167-5273(15)01226-7 \\
\hline Journal homepage & http://www.internationaljournalofcardiology.com \\
\hline Author contact & werner.budts@med.kuleuven.be \\
\hline & $+32(0) 16344302$ \\
\hline IR & https://lirias.kuleuven.be/handle/123456789/501680 \\
\hline
\end{tabular}

(article begins on next page) 


\section{Pulmonary Outflow Obstruction Protects Against Heart Failure in Adults with Congenitally Corrected Transposition of the Great Arteries}

Frederik Helsen $^{\mathrm{a}, \mathrm{b}, 1}$, Pieter De Meester ${ }^{\mathrm{a}, \mathrm{b}, 1}$, Jan Van Keer ${ }^{\mathrm{b}, 1}$, Charlien Gabriels ${ }^{\mathrm{a}, \mathrm{b}, 1}$, Alexander Van de

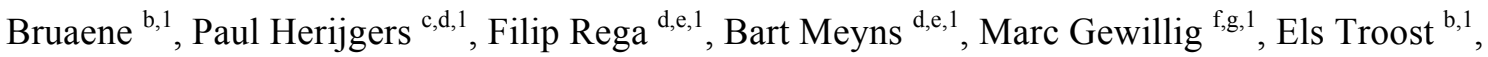
Werner Budts a,b,1,*

${ }^{a}$ Division of Cardiology, Department of Cardiovascular Sciences, KU Leuven - University of Leuven, B-3000 Leuven, Belgium

${ }^{\mathrm{b}}$ Department of Cardiology, University Hospitals Leuven, B-3000 Leuven, Belgium

${ }^{\mathrm{c}}$ Division of Experimental Cardiac Surgery, Department of Cardiovascular Sciences, KU Leuven University of Leuven, B-3000 Leuven, Belgium

${ }^{\mathrm{d}}$ Department of Cardiac Surgery, University Hospitals Leuven, B-3000 Leuven, Belgium

${ }^{\mathrm{e}}$ Division of Clinical Cardiac Surgery, Department of Cardiovascular Sciences, KU Leuven -

University of Leuven, B-3000 Leuven, Belgium

${ }^{\mathrm{f}}$ Division of Cardiovascular Developmental Biology, Department of Cardiovascular Sciences, KU Leuven - University of Leuven, B-3000 Leuven, Belgium

${ }^{\mathrm{g}}$ Department of Paediatrics, University Hospitals Leuven, B-3000 Leuven, Belgium.

\footnotetext{
${ }^{1}$ This author takes responsibility for all aspects of the reliability and freedom from bias of the data presented and their discussed interpretation.

${ }^{*}$ Corresponding author at: Adult Congenital Heart Disease, University Hospitals Leuven, Herestraat 49, B-3000 Leuven, Belgium. E-mail address: werner.budts@uzleuven.be (W. Budts).
}

This work was supported by the Agency for Innovation by Science and Technology (IWT, Flanders, Belgium) [101484] to PDM and [131025] to CG.

The authors report no relationships that could be construed as a conflict of interest.

Keywords: Congenital Heart Defects; Heart Failure; Survival; Transposition of Great Vessels; Tricuspid Valve Insufficiency 


\begin{abstract}
Background: Pulmonary outflow tract obstruction (POTO) reduces systemic atrioventricular valve (SAVV) regurgitation severity in congenitally corrected transposition of the great arteries (ccTGA). Therefore, pulmonary artery banding is proposed as a palliative intervention. We aimed to investigate the effect of native or surgically induced POTO on event-free survival, defined as the composite of all-cause mortality, heart transplantation, or congestive heart failure (CHF).

Methods and Results: Patients with ccTGA ( $\mathrm{n}=62$; median age 27.5 (IQR 18.4-39.4) years; 39\% with POTO) were selected from the Adult Congenital Heart Disease database of a tertiary hospital. At first visit, SAVV regurgitation $\geq 3 / 4$, systemic RV dysfunction $\geq$ moderate, and CHF were present in $26 \%$, $26 \%$, and $15 \%$ of patients, respectively. Over a mean follow-up time of $10.1 \pm 6.1$ years, all-cause mortality, rate of heart transplantation, and CHF were $18 \%, 8 \%$ and $40 \%$, respectively. SAVV regurgitation (HR: 1.99; 95\% CI: 1.01-3.92; $P=0.048$ ) and systemic RV dysfunction severity (HR: $1.89 ; 95 \%$ CI: $1.05-3.37 ; P=0.033)$ were associated with the composite endpoint, independently of age at baseline, POTO, Ebstein-like malformation, and systemic RV dilatation. Patients with POTO had lower risk for developing SAVV regurgitation $\geq 3 / 4$ (HR: $0.18 ; 95 \%$ CI: $0.05-0.58 ; P=0.004$ ) and moderate systemic RV dysfunction (HR: $0.34 ; 95 \% \mathrm{CI}$ : $0.15-0.78 ; P=0.011$ ). When POTO was present, the mean progression-free interval for the composite endpoint increased from 11.2 to 18.1 years $(P=0.035)$.

Conclusions: POTO is associated with an improved event-free survival in adults with ccTGA.
\end{abstract}

Keywords: Congenital Heart Defects; Heart Failure; Survival; Transposition of Great Vessels; Tricuspid Valve Insufficiency 


\section{Introduction}

Congenitally corrected transposition of the great arteries (ccTGA) is characterized by atrioventricular and ventriculo-arterial discordance. This double discordance creates a situation where the blood is normally oxygenated, but the morphological right ventricle (RV) and the systemic atrioventricular valve (SAVV) are exposed to high, systemic pressures. In about $90 \%$ of patients this congenital malformation is associated with other cardiac lesions, mostly large ventricular septal defect (VSD), pulmonary valvular or subvalvular stenosis, or morphological abnormalities of the SAVV.[1-4] Patients with ccTGA frequently develop congestive heart failure (CHF).[5] The onset of CHF is driven by a vicious circle of pressure and volume overload on the systemic RV.

However, until now the prime mover in the development of CHF has not been clearly defined. On the one hand, morphological abnormalities of the SAVV such as an Ebstein-like anomaly or a dysplasia could initiate a sequence leading to SAVV regurgitation, myocardial dysfunction and CHF.[2] In this hypothesis the volume overload from primary SAVV regurgitation is a "condicio sine qua non'. On the other hand, the continuous exposure to systemic pressure and a concordant coronary anatomy could initiate a sequence of compensatory systemic RV hypertrophy, abnormal RV myocardial perfusion, perfusion defects, and eventually myocardial dysfunction and CHF.[6, 7] SAVV regurgitation is then seen as the result of myocardial dysfunction and subsequent remodelling. The best way to avoid, or at least delay the onset of CHF in adults with ccTGA is also a matter of debate. Some authors suggest performing early SAVV surgery to preserve ventricular function.[8] Interestingly, interventions that increase subpulmonary left ventricle (LV) pressure load are associated with a reduction of SAVV regurgitation.[9-11] In addition, a favourable natural history of patients with the combination of VSD and pulmonary stenosis (PS) is noted.[12] In the 1980s a technique of retraining the subpulmonary LV by pulmonary artery banding before performing an arterial switch procedure was introduced in patients with systemic RV failure after Mustard and Senning procedures.[13] [14] Similarly, if the subpulmonary LV of a patient with ccTGA performs within a low resistance pulmonary circulation, it needs reconditioning by pulmonary artery banding before a double-switch procedure.[15] Recently, pulmonary artery banding has been performed as an open-end 
palliation of patients with a systemic RV with good mid-term follow-up results.[16-18] However, there is a lack of data on long-term outcome.

Therefore, the aim of this retrospective study was to investigate the proposed protective effect of pulmonary outflow tract obstruction (POTO) on event-free survival, defined as the composite of all-cause mortality, heart transplantation, or congestive heart failure (CHF).

\section{Methods}

\subsection{Patient selection and data collection}

The records of all patients with isolated or complex ccTGA were retrieved from the Adult Congenital Heart Disease database of the University Hospitals Leuven, a tertiary care centre specialized in congenital heart disease. All files from January 1990 to January 2015 were retrospectively reviewed. Patients with a single ventricle, those who had undergone a double-switch operation, or those without at least one follow-up visit at our clinic were excluded. Baseline variables were documented at the first patient contact, defined as the moment of transfer out of paediatric care at the age of $16-18$ years, at first referral to the Adult Congenital Heart Disease clinic, or at the moment of the oldest retrievable echocardiographic exam if the patient follow-up started before 1990. For patient with SAVV prosthesis, the degree of SAVV regurgitation prior to valve replacement is reported.

The study protocol conforms to the ethical guidelines of the 1975 Declaration of Helsinki. The local institutional review committee approved the study and waived informed consent.

\subsection{Echocardiographic data}

Comprehensive 2-dimensional echocardiographic examinations were performed and analysed in our institution by two senior cardiologists specialized in Adult Congenital Heart Disease (E.T. and W.B.). The SAVV was considered morphologically abnormal if there was evidence of structural abnormalities such as an Ebstein-like malformation, prolapse of valve leaflets, or dysplastic features. SAVV regurgitation severity was semiquantitatively assessed by Doppler colour flow mapping on the basis of size of the jet and reversal of flow in the pulmonary veins, and severity was graded on a scale 
from 0 to 4.[19] Clinically important SAVV regurgitation was defined as SAVV regurgitation $\geq 3 / 4$.[2, 5] Systemic RV function and systemic RV dilatation were qualitatively assessed using an integrative multi-view approach, and impairment was graded on a scale from 0 to 3 . Clinically important systemic RV dysfunction or dilatation was defined as at least moderate dysfunction or dilatation $(\geq 2 / 3)$. POTO was defined as an instantaneous peak Doppler pressure gradient $\geq 30 \mathrm{mmHg}$ in the subpulmonary LV outflow tract at rest. According to the pressure gradient, the patients were divided in 4 categories ( $<30 \mathrm{mmHg}, 30-59 \mathrm{mmHg}, 60-89 \mathrm{mmHg}$, and $\geq 90 \mathrm{mmHg}$ ).[20] The VSD size was estimated by echocardiography. The VSD was considered large if the defect size was associated with non-restrictive flow. All patients with a history of VSD, independent of VSD closure in childhood, were classified into the category (repaired) VSD.

\subsection{Endpoints}

Outcome analysis focused on the all-cause mortality, the need for heart transplantation, and the occurrence of CHF. CHF was diagnosed when the patient presented with the combination of relevant symptoms (i.e., New York Heart Association functional class III or IV), signs (i.e., elevated jugular venous pressure, hepatomegaly, pulmonary crackles, ankle swelling), an increase in cardiothoracic ratio compared to a previous chest X-ray, and evidence of fluid overload on echocardiography or elevated NT-proBNP levels. The development of SAVV regurgitation $\geq 3 / 4$ and moderate systemic RV dysfunction was also reviewed.

\subsection{Statistical analysis}

Categorical variables are expressed as numbers and percentages. Continuous data are presented as mean $\pm \mathrm{SD}$ or as median with interquartile range (IQR). Data were tested for normal distribution with the Shapiro-Wilk test. Differences between 2 groups for continuous variables were analysed using unpaired t-test or Wilcoxon-Mann-Whitney test, as appropriate; Fisher's exact test was used for categorical variables. To quantify correlations between two variables, the Pearson correlation test or the point-biserial correlation test was used. For the purpose of statistical analysis, the degrees of SAVV regurgitation, systemic RV dysfunction and systemic RV dilatation were considered a 
continuous variable. For time-to-event analyses, time 0 was defined as time of first documented visit to the Adult Congenital Heart Disease clinic. The time to the occurrence of a given event was documented in years, with censoring at the time of latest follow-up. Uni- and multivariate Cox regression analyses were performed to identify baseline characteristics associated with the development of the endpoints. Only those univariate variables with $\mathrm{P}<0.05$ were subsequently entered into multivariate models. Hazard ratios (HRs) are presented with 95\% confidence intervals (CIs). Kaplan-Meier analyses with log-rank testing were performed to assess the differences in event-free survival.

All statistical tests were 2 -sided, and a P-value $<0.05$ was considered statistically significant. Analyses were performed using IBM SPSS Statistics, version 20.

\section{Results}

\subsection{Patient demographics and baseline characteristics}

The records of 70 patients with isolated or complex ccTGA were examined for eligibility. After reviewing all records, 62 patients were found eligible and included in the study. Patients were excluded for the following reasons: four had a single ventricle, one had undergone a double-switch operation, and three visited the Adult Congenital Heart Disease clinic just once.

Table 1 summarizes baseline characteristics, both for the total patient cohort and for the patient groups with and without POTO. Median age at first presentation was 27.5 (IQR 18.4-39.4) years. The most frequent associated anomalies were (repaired) VSD, structural abnormal SAVV, and POTO. The reasons for POTO were native pulmonary valvular or subvalvular stenosis (71\%), pulmonary artery banding (13\%), and conduit or pulmonary homograft stenosis $(17 \%)$. Of these patients, 7 had a gradient of 30-59 $\mathrm{mmHg}, 7$ had a gradient of $60-89 \mathrm{mmHg}$, and 10 had a gradient of $\geq 90 \mathrm{mmHg}$. The mean resting oxygen saturation in patients with a residual VSD was $93 \pm 5 \%$ (data from 1 patient is missing). Five patients with a residual VSD had resting oxygen saturation $<90 \%$, ranging from 79 to $89 \%$. Clinically important SAVV regurgitation, systemic RV dysfunction, or RV dilatation were present in $26 \%, 26 \%$, and $68 \%$ of patients, respectively. Figure 1 depicts the variation 
in the degree of SAVV regurgitation depending on the presence or absence of POTO. Predefined CHF was present in 15\%; the median age in this subgroup was 47.0 (IQR 20.3-56.1) years.

\subsection{Outcome}

Survival status was obtained of $57(92 \%)$ patients. Mean follow-up time was $10.1 \pm 6.1$ years. The composite endpoint of death, heart transplantation, or CHF occurred in $40 \%$ of patients. All-cause mortality was $18 \%$ with a mean age of death of $52.2 \pm 15.2$ years, rate of heart transplantation was $8 \%$ with a mean age at transplantation of $32.2 \pm 11.5$ years, and $40 \%$ of patients were diagnosed with CHF with a mean age of $42.8 \pm 15.8$ years at diagnosis. Patients with a pressure gradient in the subpulmonary LV outflow tract of 30 to $59 \mathrm{mmHg}$ experienced no clinical events. At latest follow-up, $44 \%$ of patients had clinically important SAVV regurgitation and $57 \%$ had clinically important systemic RV dysfunction. Detailed results are listed in Table 2.

3.3 Variables related with the composite endpoint of death, heart transplantation, or congestive heart failure

On multivariate Cox regression analysis, the degrees of SAVV regurgitation (HR: 1.99; 95\% CI: 1.01-3.92; $P=0.048$ ) and systemic RV dysfunction (HR: $1.89 ; 95 \% \mathrm{CI}: 1.05-3.37 ; P=0.033$ ) were associated with the composite endpoint, independently of age at baseline, POTO, Ebstein-like malformation, and the degree of systemic RV dilatation. All risk factors examined are listed in Table 3.

There was a moderate positive relationship between the degrees of SAVV regurgitation and systemic RV dysfunction at baseline ( $\mathrm{r} 0.31 ; P=0.016)$. Because we found a strong negative relationship between the degrees of SAVV regurgitation and POTO $\left(\mathrm{r}_{\mathrm{pb}}-0.57 ; P<0.001\right)$, we decided to assess the relationship of SAVV regurgitation and systemic RV dysfunction in the group with and without POTO separately. The positive relationship between the degree of SAVV regurgitation and the degree of systemic RV dysfunction stayed present in the group without POTO, but it was completely absent in the group with POTO (r $0.36 ; P=0.026$ and $\mathrm{r}-0.68 ; P=0.757$, respectively). In order to better understand the mechanisms that have a positive or negative influence on the 
development of clinically important SAVV regurgitation and systemic RV dysfunction, we performed further Cox regression analyses.

\subsection{Variables related with development of clinically important SAVV regurgitation}

Patients with POTO had lower risk of developing clinically important SAVV regurgitation (HR: 0.18; 95\% CI: $0.05-0.58 ; P=0.004)$. The degrees of systemic RV dysfunction (HR: $1.59 ; 95 \%$ CI: $1.02-$ 2.46; $P=0.039$ ), RV dilatation (HR: $1.95 ; 95 \% \mathrm{CI}: 1.01-3.45 ; P=0.022$ ), and a residual large VSD (HR: $0.23 ; 95 \%$ CI: $0.06-0.99 ; P=0.048$ ) were also associated with the development of clinically important SAVV regurgitation.

\subsection{Variables related with development of clinically important systemic $R V$ dysfunction}

Patients with POTO had lower risk of developing clinically important systemic RV dysfunction (HR: 0.34; 95\% CI: $0.15-0.78 ; P=0.011$ ). The degrees of SAVV regurgitation (HR: $1.77 ; 95 \%$ CI: $1.17-$ 2.66; $P=0.006$ ), systemic RV dilatation (HR: $1.89 ; 95 \% \mathrm{CI}: 1.13-3.18 ; P=0.016$ ), and residual large VSD (HR: $0.28 ; 95 \%$ CI: $0.10-0.80 ; P=0.018)$ were also associated with the development of clinically important systemic RV dysfunction.

\subsection{Event-free survival analyses stratified for pulmonary outflow tract obstruction}

Mean progression-free survival for developing clinically important SAVV regurgitation or systemic RV dysfunction was significantly longer in the group with POTO than in the group without POTO (20.7 vs. 8.7 years; $P=0.001$ and 16.3 vs. 6.5 years; $P=0.005$, respectively). Moreover, mean progression-free survival for the composite endpoint of all-cause mortality, heart transplantation, or CHF was also significantly longer in the group with POTO than in the group without POTO (18.1 vs. 11.2 years; $P=0.035)$. Figure 2 illustrates the Kaplan-Meier survival curves plotted according to POTO status. The influence of the different degrees of POTO on the composite endpoint is illustrated in Figure 3. When we consider the patients with POTO and a residual large VSD (13 patients) versus POTO without a residual large VSD (11 patients), there was no difference in the composite endpoint (mean progression-free survival 16.0 vs. 18.4 years; log-rank $\mathrm{p}=0.585$ ). 


\section{Discussion}

In the present study, we showed that POTO was inversely correlated with the degree of SAVV regurgitation. Moreover, POTO was associated with a slower progression to clinically important SAVV regurgitation and systemic RV dysfunction, and an improved morbidity and mortality rate on long-term follow-up of adults with ccTGA.

Congenitally corrected transposition of the great arteries is a congenital heart defect associated with important morbidity and mortality.[2, 4, 5, 21, 22] The relation between SAVV regurgitation, systemic RV dysfunction, and CHF is not completely understood.[4, 5, 23] In the study of Prieto et al.[2], clinically important SAVV regurgitation seemed to be responsible for the occurrence of CHF. However, in our study both SAVV regurgitation and systemic RV dysfunction were the main drivers of the composite endpoint of all-cause mortality, heart transplantation, or CHF. Prieto et al.[2] found, in patients followed from birth to early adulthood, that a morphological abnormal SAVV was the only factor associated with the development of clinically important SAVV regurgitation and that systemic RV dysfunction appeared almost always secondary to long-standing SAVV regurgitation. Our data seem to contradict these findings. By reviewing the data more into detail, Prieto et al.[2] did not take in account the presence of POTO, whereas in our study a substantial number of patients did have POTO. Moreover, our study indicates that POTO is inversely associated with the degree of SAVV regurgitation and provides evidence that POTO protects against clinically important SAVV regurgitation and systemic RV dysfunction. By delaying the onset of clinically important SAVV regurgitation and systemic RV dysfunction, POTO can postpone the onset of CHF, as proven by our data.

Over the last decade, the congenital heart surgeons of our institution perform pulmonary artery (dilatable) banding on all asymptomatic patients when they are about 7 years old. Theoretically, POTO increases the afterload of the morphological LV, which counteracts the shift of the interventricular septum towards the morphological LV. This septal shift results in a less spherical systemic RV, a less distorted subvalvular SAVV complex, and a reduced SAVV regurgitation 
severity.[10] As a consequence, by avoiding volume overload from the SAVV regurgitation, the systemic RV is longer exposed to an isolated systemic pressure load. This could explain why we found that clinically important SAVV regurgitation, systemic RV dysfunction, and the composite endpoint occurred significantly later in this subset of patients. Considering the results of our study, pulmonary artery banding could gain importance over the following years.

\section{Limitations}

This study has some limitations. First, this was a retrospective, single-institution cohort study with a limited number of patients. Secondly, the study was designed to evaluate outcomes of patients with ccTGA visiting the Adult Congenital Heart Disease clinic. Some patients were directly transferred from Paediatric Cardiology to the Adult Congenital Heart Disease clinic, others were referred at later age. At inclusion, a considerable number had systemic RV dysfunction, SAVV regurgitation, and some were already suffering from CHF episodes. However, this heterogeneity reflects well the patient population that is seen by adult congenital heart specialists. Thirdly, echocardiographic assessment of RV function was mostly qualitative. Metrics of longitudinal RV shortening were available in some patients, however the contraction pattern of the systemic RV is predominately circumferential and radial.[24, 25] Qualitative estimation of systemic RV function correlates relatively well with cardiac MRI-derived EF, although the best results are found in comparisons between mild and severe impairment.[26] To minimize interobserver variability, all assessments of ventricular function were done by two expert readers. Fourthly, the diagnosis of CHF is difficult in patients with a systemic RV and the value of BNP and NT-proBNP unclear in this population.[27] Therefore, we relied on the clinical judgement of the treating congenital cardiologist. Last, patients numbers in the different categories of POTO are limited, thus the results presented in Figure 3 are merely hypothesis generating. 


\section{Conclusions}

In conclusion, POTO is a protective factor in patients with ccTGA. It is associated with a slower progression of SAVV regurgitation and systemic RV dysfunction, thus delaying morbidity and mortality. Furthermore, these results feed the hypothesis that pulmonary artery banding can be a palliative intervention in patients without POTO.

\section{References}

[1] Warnes CA. Transposition of the great arteries. Circulation. 2006;114:2699-709.

[2] Prieto LR, Hordof AJ, Secic M, Rosenbaum MS, Gersony WM. Progressive tricuspid valve disease in patients with congenitally corrected transposition of the great arteries. Circulation. 1998;98:997-1005.

[3] Lundstrom U, Bull C, Wyse RK, Somerville J. The natural and "unnatural" history of congenitally corrected transposition. Am J Cardiol. 1990;65:1222-9.

[4] Connelly MS, Liu PP, Williams WG, Webb GD, Robertson P, McLaughlin PR. Congenitally corrected transposition of the great arteries in the adult: functional status and complications. J Am Coll Cardiol. 1996;27:1238-43.

[5] Graham TP, Bernard YD, Mellen BG, Celermajer D, Baumgartner H, Cetta F, et al. Long-term outcome in congenitally corrected transposition of the great arteries: a multi-institutional study. J Am Coll Cardiol. 2000;36:255-61.

[6] Hornung TS, Bernard EJ, Celermajer DS, Jaeggi E, Howman-Giles RB, Chard RB, et al. Right ventricular dysfunction in congenitally corrected transposition of the great arteries. Am J Cardiol. 1999;84:1116-9, A10.

[7] Hauser M, Bengel FM, Hager A, Kuehn A, Nekolla SG, Kaemmerer H, et al. Impaired myocardial blood flow and coronary flow reserve of the anatomical right systemic ventricle in patients with congenitally corrected transposition of the great arteries. Heart. 2003;89:1231-5. 
[8] Mongeon FP, Connolly HM, Dearani JA, Li Z, Warnes CA. Congenitally corrected transposition of the great arteries ventricular function at the time of systemic atrioventricular valve replacement predicts long-term ventricular function. J Am Coll Cardiol. 2011;57:2008-17.

[9] Acar P, Sidi D, Bonnet D, Aggoun Y, Bonhoeffer P, Kachaner J. Maintaining tricuspid valve competence in double discordance: a challenge for the paediatric cardiologist. Heart. 1998;80:479-83. [10] Kral Kollars CA, Gelehrter S, Bove EL, Ensing G. Effects of morphologic left ventricular pressure on right ventricular geometry and tricuspid valve regurgitation in patients with congenitally corrected transposition of the great arteries. Am J Cardiol. 2010;105:735-9.

[11] Koh M, Yagihara T, Uemura H, Kagisaki K, Kitamura S. Functional biventricular repair using left ventricle-pulmonary artery conduit in patients with discordant atrioventricular connections and pulmonary outflow tract obstruction-does conduit obstruction maintain tricuspid valve function? Eur J Cardiothorac Surg. 2004;26:767-72.

[12] Hraska V, Duncan BW, Mayer JE, Freed M, del Nido PJ, Jonas RA. Long-term outcome of surgically treated patients with corrected transposition of the great arteries. J Thorac Cardiovasc Surg. 2005;129:182-91.

[13] Mee RB. Severe right ventricular failure after Mustard or Senning operation. Two-stage repair: pulmonary artery banding and switch. J Thorac Cardiovasc Surg. 1986;92:385-90.

[14] Poirier NC, Yu JH, Brizard CP, Mee RB. Long-term results of left ventricular reconditioning and anatomic correction for systemic right ventricular dysfunction after atrial switch procedures. J Thorac Cardiovasc Surg. 2004;127:975-81.

[15] Quinn DW, McGuirk SP, Metha C, Nightingale P, de Giovanni JV, Dhillon R, et al. The morphologic left ventricle that requires training by means of pulmonary artery banding before the double-switch procedure for congenitally corrected transposition of the great arteries is at risk of late dysfunction. J Thorac Cardiovasc Surg. 2008;135:1137-44, 44.e1-2.

[16] Cools B, Brown SC, Louw J, Heying R, Meyns B, Gewillig M. Pulmonary artery banding as 'open end' palliation of systemic right ventricles: an interim analysis. Eur J Cardiothorac Surg. 2012;41:913-8. 
[17] Winlaw DS, McGuirk SP, Balmer C, Langley SM, Griselli M, Stümper O, et al. Intention-to-treat analysis of pulmonary artery banding in conditions with a morphological right ventricle in the systemic circulation with a view to anatomic biventricular repair. Circulation. 2005;111:405-11. [18] Ma K, Gao H, Hua Z, Yang K, Hu S, Zhang H, et al. Palliative pulmonary artery banding versus anatomic correction for congenitally corrected transposition of the great arteries with regressed morphologic left ventricle: Long-term results from a single center. J Thorac Cardiovasc Surg. 2014;148:1566-71.

[19] Lancellotti P, Moura L, Pierard LA, Agricola E, Popescu BA, Tribouilloy C, et al. European Association of Echocardiography recommendations for the assessment of valvular regurgitation. Part 2: mitral and tricuspid regurgitation (native valve disease). Eur J Echocardiogr. 2010;11:307-32. [20] Honjo O, Kotani Y, Bharucha T, Mertens L, Caldarone CA, Redington AN, et al. Anatomical factors determining surgical decision-making in patients with transposition of the great arteries with left ventricular outflow tract obstruction. Eur J Cardiothorac Surg. 2013;44:1085-94; discussion 94. [21] Beauchesne LM, Warnes CA, Connolly HM, Ammash NM, Tajik AJ, Danielson GK. Outcome of the unoperated adult who presents with congenitally corrected transposition of the great arteries. $\mathrm{J}$ Am Coll Cardiol. 2002;40:285-90.

[22] Rutledge JM, Nihill MR, Fraser CD, Smith OE, McMahon CJ, Bezold LI. Outcome of 121 patients with congenitally corrected transposition of the great arteries. Pediatr Cardiol. 2002;23:13745.

[23] De Meester P, Budts W, Meyns B, Gewillig M. The Tricuspid Valve in Congenitally Corrected Transposition of the Great Arteries. In: Giamberti A, Chessa M, editors. The Tricuspid Valve in Congenital Heart Disease. Germany: Springer; 2014. p. 107-19.

[24] Pettersen E, Helle-Valle T, Edvardsen T, Lindberg H, Smith HJ, Smevik B, et al. Contraction pattern of the systemic right ventricle shift from longitudinal to circumferential shortening and absent global ventricular torsion. J Am Coll Cardiol. 2007;49:2450-6.

[25] Di Salvo G, Pacileo G, Rea A, Limongelli G, Baldini L, D'Andrea A, et al. Transverse strain predicts exercise capacity in systemic right ventricle patients. Int J Cardiol. 2010;145:193-6. 
[26] Salehian O, Schwerzmann M, Merchant N, Webb GD, Siu SC, Therrien J. Assessment of systemic right ventricular function in patients with transposition of the great arteries using the myocardial performance index: comparison with cardiac magnetic resonance imaging. Circulation. 2004;110:3229-33.

[27] Eindhoven JA, van den Bosch AE, Jansen PR, Boersma E, Roos-Hesselink JW. The usefulness of brain natriuretic peptide in complex congenital heart disease: a systematic review. J Am Coll Cardiol. 2012;60:2140-9. 
Table 1. Demographic and clinical variables at inclusion

\begin{tabular}{|c|c|c|c|c|}
\hline Baseline variable & $\begin{array}{l}\text { Total population } \\
\qquad(\mathrm{n}=62)\end{array}$ & $\begin{array}{l}\text { POTO absent } \\
\quad(n=38)\end{array}$ & $\begin{array}{l}\text { POTO present } \\
(\mathrm{n}=24)\end{array}$ & $P$-value \\
\hline Age at first visit, median (IQR), y & $27.5(18.4-39.4)$ & $28.0(19.3-40.1)$ & $25.2(18.0-36.2)$ & 0.452 \\
\hline Female gender, $\mathrm{n}(\%)$ & $18(29)$ & $10(26)$ & $8(33)$ & 0.578 \\
\hline \multicolumn{5}{|l|}{ Associated anomalies, n (\%) } \\
\hline (Repaired) VSD & $36(58)$ & $13(34)$ & $23(96)$ & $<0.001^{*}$ \\
\hline (Repaired) large VSD & $32(52)$ & $11(29)$ & $21(88)$ & $<0.001^{*}$ \\
\hline Residual VSD & $19(31)$ & $4(11)$ & $15(63)$ & $<0.001^{*}$ \\
\hline Residual large VSD & $16(26)$ & $3(8)$ & $13(54)$ & $<0.001^{*}$ \\
\hline POTO & $24(39)$ & & & \\
\hline Morphologic abnormal SAVV & $34(55)$ & $19(50)$ & $15(63)$ & 0.434 \\
\hline Ebstein-like malformation & $20(32)$ & $12(32)$ & $8(33)$ & $>0.999$ \\
\hline Pacemaker, n $(\%)$ & $9(15)$ & $7(18)$ & $2(8)$ & 0.462 \\
\hline Previous OHS, n (\%) & $23(37)$ & $12(32)$ & $11(46)$ & 0.291 \\
\hline Previous CHF episode, $\mathrm{n}(\%)$ & $9(15)$ & $8(21)$ & $1(4)$ & 0.135 \\
\hline NYHA functional class, I/II/III/IV, n & $41 / 16 / 5 / 0$ & $25 / 9 / 4 / 0$ & $16 / 7 / 1 / 0$ & 0.634 \\
\hline Residual large VSD absent & $32 / 9 / 5 / 0$ & $24 / 7 / 4 / 0$ & $8 / 2 / 1 / 0$ & \\
\hline Residual large VSD present & $9 / 7 / 0 / 0$ & $1 / 2 / 0 / 0$ & $8 / 5 / 0 / 0$ & \\
\hline Presence of CHF signs, $\mathrm{n}(\%)$ & $4(7)$ & $4(11)$ & $0(0)$ & $<0.001^{*}$ \\
\hline Residual large VSD absent & $4(9)$ & $4(11)$ & $0(0)$ & \\
\hline Residual large VSD present & $0(0)$ & $0(0)$ & $0(0)$ & \\
\hline \multicolumn{5}{|l|}{ SAVV regurgitation } \\
\hline$\geq 3 / 4, \mathrm{n}(\%)$ & $16(26)$ & $16(42)$ & $0(0)$ & $<0.001^{*}$ \\
\hline
\end{tabular}


Degree, median (IQR)

Systemic RV Dysfunction

$\geq$ Moderate, n (\%)

Degree, median (IQR), /3

Systemic RV Dilatation

$\geq$ Moderate, n (\%)

Degree, median (IQR), /3
$2(1.5-3)$

$2.5(2-3)$

$1.5(1-2)$

$<0.001^{*}$

16(26)

$12(32)$

$4(17)$

0.242

$1(0-2)$

$1(0.5-2)$

$0.5(0-1)$

$0.048^{*}$

CHF, congestive heart failure; IQR, interquartile range; $n$, number of patients; OHS, open heart surgery; POTO, pulmonary outflow tract obstruction; RV, right ventricular; SAVV, systemic atrioventricular valve; VSD, ventricular septal defect; y, years.

*Statistically significant.
$42(68)$

$28(74)$

$14(58)$

0.268

$2(1-2)$

$2(1-2)$

$2(1-2)$

0.094 
Table 2. Outcome

Total population $(n=62)$

\begin{tabular}{lc}
\hline $\begin{array}{l}\text { Follow-up time, mean } \pm \text { SD, y } \\
\text { median (IQR) }\end{array}$ & $10.1 \pm 6.1$ \\
All-cause mortality, n (\%) & $11(18)$ \\
CV mortality, n/all-cause & $7(64)$ \\
mortality (\%) & $5(8)$ \\
HTx, n (\%) & $25(40)$ \\
CHF, n (\%) & $25(40)$ \\
Composite of all-cause \\
mortality, HTx, or CHF, $\mathrm{n}(\%)$ \\
SAVV regurgitation $\geq 3 / 4$ at \\
last follow-up, $\mathrm{n}(\%)$ \\
Moderate systemic RV \\
dysfunction at last follow-up, \\
n(\%)
\end{tabular}

$\mathrm{CV}$, cardiovascular; CHF, congestive heart failure; HTx, heart transplantation; IQR, interquartile range; n, number of patients; RV, right ventricular; SAVV, systemic atrioventricular valve; SD, standard deviation; y, years. 
Table 3. Baseline variables related with the composite endpoint of death, heart transplantation, or congestive heart failure

\begin{tabular}{|c|c|c|c|c|c|c|}
\hline \multirow[t]{2}{*}{ Variable } & \multicolumn{3}{|c|}{ Univariate analyses } & \multicolumn{3}{|c|}{ Multivariate analysis } \\
\hline & HR & $95 \% \mathrm{CI}$ & $P$-value & HR & $95 \% \mathrm{CI}$ & $P$-value \\
\hline Age at first visit & 1.05 & $1.02-1.08$ & $0.001^{*}$ & 1.03 & $0.99-1.07$ & 0.069 \\
\hline Female gender & 0.63 & $0.23-1.69$ & 0.361 & & & \\
\hline Associated anomalies & & & & & & \\
\hline (Repaired) VSD & 0.71 & $0.31-1.60$ & 0.408 & & & \\
\hline (Repaired) Large VSD & 0.83 & $0.37-1.86$ & 0.651 & & & \\
\hline Residual large VSD & 0.92 & $0.38-2.21$ & 0.844 & & & \\
\hline Pulmonary outflow obstruction & 0.38 & $0.15-0.98$ & $0.046^{*}$ & 0.75 & $0.22-2.52$ & 0.640 \\
\hline Morphologic abnormal SAVV & 0.88 & $0.40-1.95$ & 0.760 & & & \\
\hline Ebstein-like malformation & 0.33 & $0.11-0.96$ & $0.042 *$ & 0.38 & $0.10-1.42$ & 0.150 \\
\hline Previous OHS & 1.25 & $0.56-2.80$ & 0.582 & & & \\
\hline Pacemaker & 1.54 & $0.58-4.13$ & 0.387 & & & \\
\hline Degree of SAVV regurgitation & 2.13 & $1.33-3.41$ & $0.002 *$ & 1.99 & $1.01-3.92$ & $0.048^{*}$ \\
\hline Degree of systemic RV dysfunction & 2.18 & $1.40-3.38$ & $0.001 *$ & 1.89 & $1.05-3.37$ & $0.033^{*}$ \\
\hline Degree of systemic RV dilatation & 1.87 & $1.01-3.48$ & $0.047^{*}$ & 1.01 & $0.55-1.82$ & 0.985 \\
\hline
\end{tabular}

CI, confidence interval; HR, hazard ratio; n, number of patients; OHS, open heart surgery; RV, right ventricular; SAVV, systemic atrioventricular valve; VSD, ventricular septal defect.

*Statistically significant. 
Figure 1. Boxplot of the degree of SAVV regurgitation for patients with or without pulmonary outflow tract obstruction.

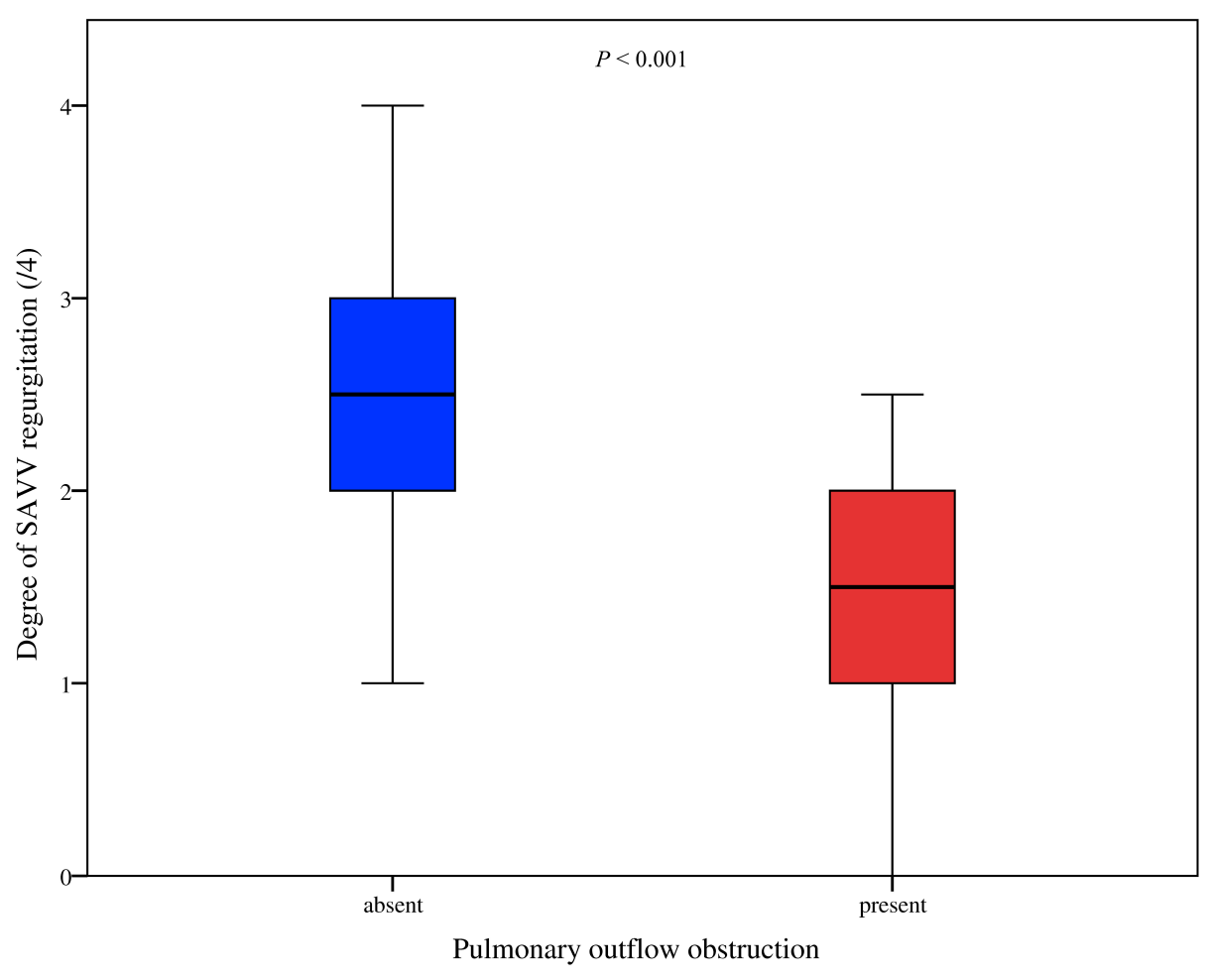


Figure 2. Kaplan-Meier estimates for event-free survival, i.e. SAVV regurgitation $\geq 3 / 4$ (A), moderate systemic RV dysfunction (B), and the composite endpoint of death, heart transplantation, or CHF (C). Comparison according to the presence or absence of pulmonary outflow tract obstruction at baseline.

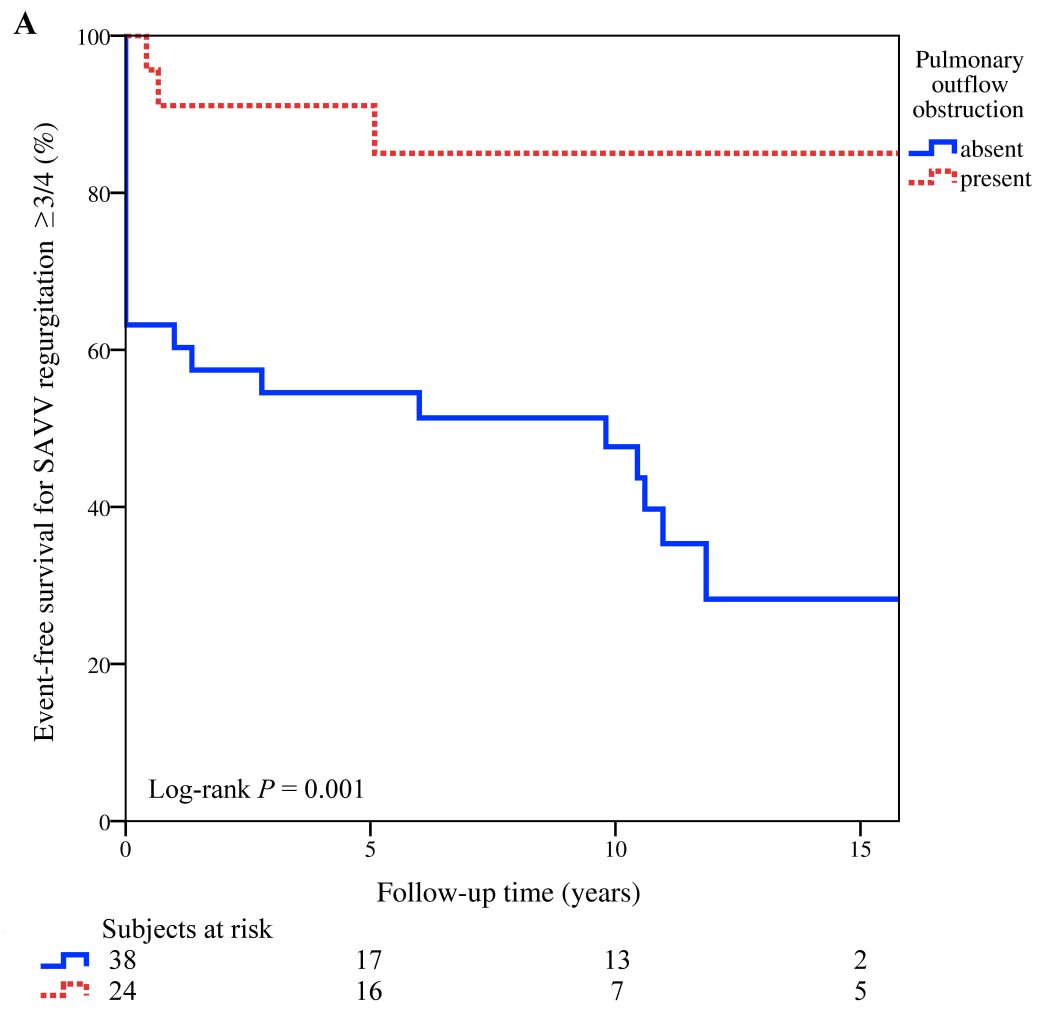


B

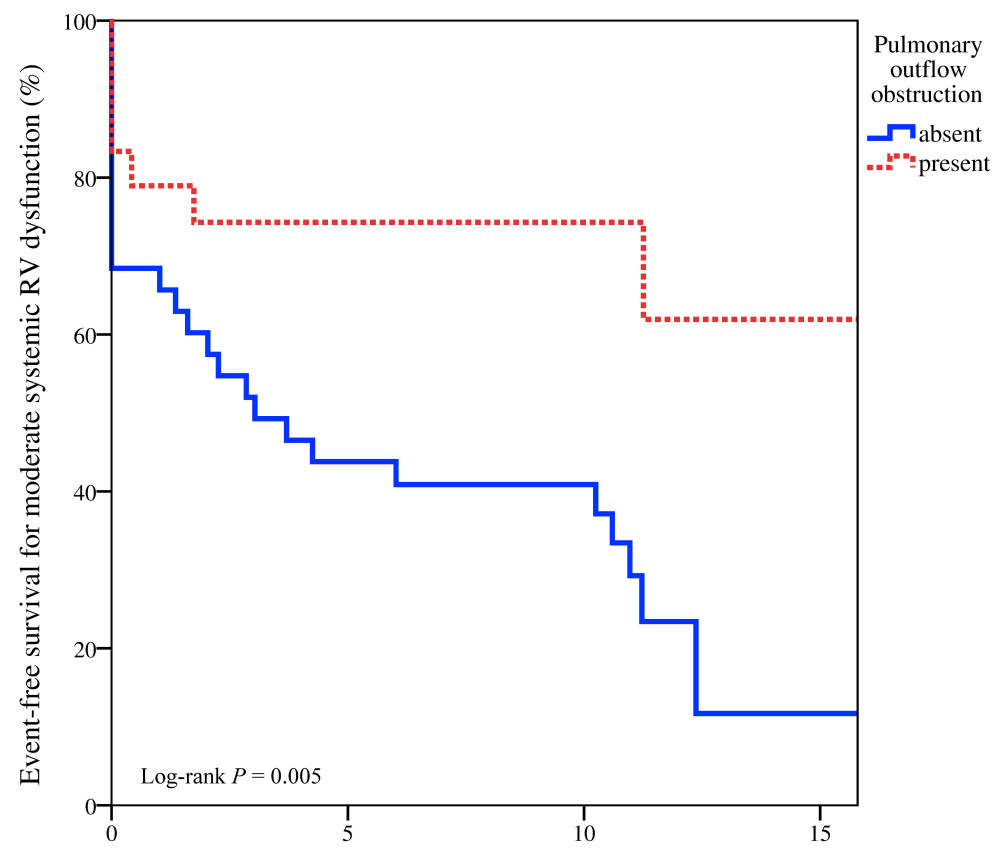

Subjects at risk Follow-up time (years)

$\begin{array}{cccc}\text { ח-."- } 38 & 15 & 11 & 1 \\ 24 & 13 & 7 & 5\end{array}$

C

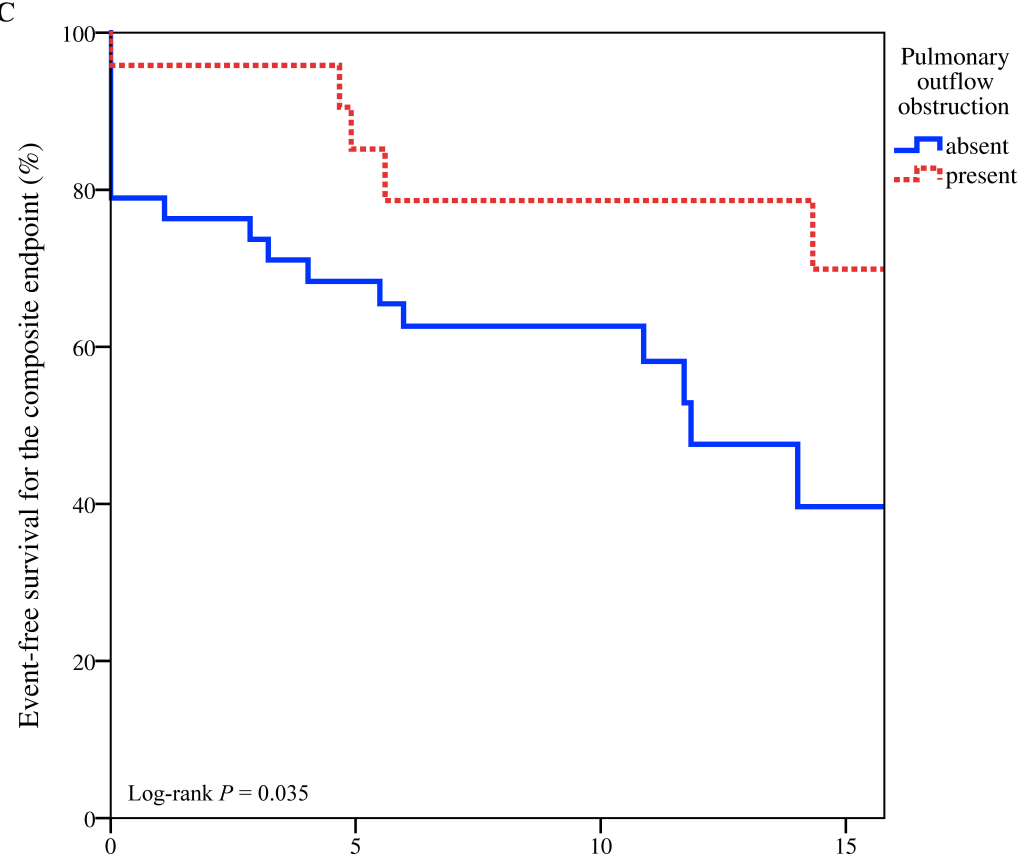

Subjects at risk

ת 38

$\begin{array}{llll}\text { ח." } 38 & 24 & 16 & 4 \\ 24 & 16 & 10 & 8\end{array}$

Follow-up time (years) 
Figure 3. Kaplan-Meier estimates for the composite endpoint of death, heart transplantation, or CHF.

Comparison according to the degree of pulmonary outflow tract obstruction at baseline.

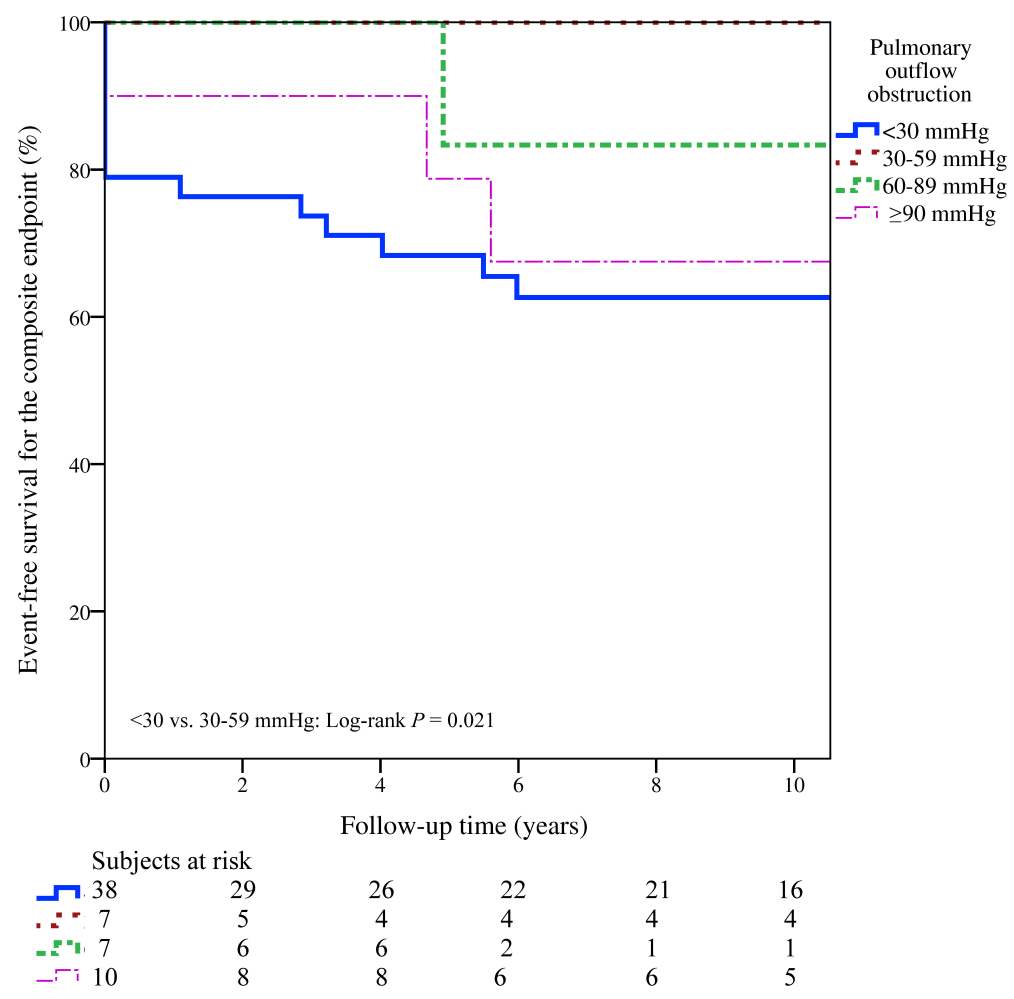

